\title{
Awareness Level on Mental IIIness Among Secondary School Students in Skudai, Johor
}

\author{
Nik Murni Nik Mustafa, Hadina Habil, Noor Aireen Ibrahim, Hanita Hassan
}

Language Academy, University Teknologi Malaysia, Skudai, Malaysia

Email address:

nikumurni@gmail.com (N. M. N. Mustafa), hadina@utm.my (H. Habil)

\section{To cite this article:}

Nik Murni Nik Mustafa, Hadina Habil, Noor Aireen Ibrahim, Hanita Hassan. Awareness Level on Mental Illness among Secondary School Students in Skudai, Johor. Psychology and Behavioral Sciences. Vol. 4, No. 5, 2015, pp. 181-189. doi: 10.11648/j.pbs.20150405.12

\begin{abstract}
Adolescents diagnosed with mental illness in Malaysia have increased these past few years despite various health campaigns and awareness programs organised by the government and private sectors. Thus, this research aims to investigate the students' awareness level and perception on mental illness. Questionnaires have been distributed to 118 form four secondary school students in Skudai, Johor. Findings from the study show that most of the respondents are fairly ignorant of mental illness and they revealed that the promotion of mental health and wellness is still lacking in Malaysia. They also believed that mental illness is still being surrounded with stigma and discrimination over the years. Nonetheless, the respondents have relatively positive views on mental health patients and the illness itself.
\end{abstract}

Keywords: Awareness Level, Attitude, Mental Illness, Secondary School Students

\section{Introduction}

Mental health is one of the important aspects in one's life apart from physical, spiritual and financial well being. Healthy mind is believed to be a key in achieving satisfaction in an individual's life [1]. This shows that good mental health is essential in one's life as a person will be able to cope with the normal stresses of everyday life, able to work efficiently and fruitfully and can contribute to the society.

In general, mental illness is a health problem that affects a person's thinking, feeling, and ability to relate and interact with others as well as their daily performance. These illnesses often result in a limited capability in coping with ordinary demands of life. Mental illness is also reported to start as early as in adolescence based on national study of adults with mental health disorder [2].

Mental health is as important as physical health to a person's well-being. It is crucial particularly during the turbulent years of adolescence as it is a stage of life full of opportunities and risks. This is because the brain undergoes a significant period of growth and development during adolescence which continues into the twenties. During this stage, the adolescents are passing through a vulnerable time of neurodevelopment that can have a serious impact in all aspects of their life [3]. This mean the quality of the adolescence that a person lives can have long-term consequences for the individual as well as for the society.

Several previous studies have implied that mental illness is indeed prevalence among children. It was reported that the number of cases of mental health problems among students are indeed on the rise every year [4]. In addition, mental health issues are also predicted to increase by $15 \%$ by 2020 with youth as the main target group who are at risk of suffering this disorder according to the report [5]. Hence, these issues were undeniably often being debated both nationally and globally.

In Malaysia, there have also been a few research conducted in relation to mental illness. According to a survey, it was found that the prevalence of psychiatric morbidity to be $11.2 \%$ for adults (aged 16 and above) while the rate for children and adolescents (aged 15 and below) is much higher at $20.3 \%$. Even though this survey does not reflect the extent of mental disorders among Malaysians, yet it indicates that many Malaysians are indeed not in a state of mental wellbeing [6]. Another survey has also been conducted which revealed that the prevalence rate of depression among 243 Malaysian lower secondary school girls was 14\% [7].

In addition, Datuk Seri Liow Tiong Lai, Malaysia Health Minister stated that mental health issues is viewed seriously by The Health Ministry especially the rising trend among adolescents and children aged 15 and below by referring to statistics of mental health problems involving the group rose to $13 \%$ in $1996,19.4 \%$ in 2006 and $20 \%$ in 2011 [8]. This 
was supported with the pilot study conducted in collaboration with the Ministry of Health on mental health of secondary school children which indicated that $17.1 \%$ of the students had symptoms suggestive of severe anxiety disorders, while $5.2 \%$ of them had severe depression [9]. This statistic reflects the rising trend of mental illness cases among Malaysian including teenagers.

Mental illness could bring serious impact to the students' life as they are passing through a vulnerable time of neurodevelopment. This disorder could cause an unnecessary obstacle and impact to the students' daily functioning in classroom. Studies reveal that most students who are mentally unstable and suffer from poor social-emotional functioning have difficulty to achieve excellent academic standards [3]. The most common problem faced by mental illness sufferers is stigma and discrimination which would lead to negative feedback in the classroom. All of these negative views can affect teachers, classmates, and peers' reaction and attitude towards the students who suffer from mental disorder. The stigma and discrimination faced by mental illness patients stem from the lack of public awareness and understanding about this illness [10].

Moreover, research has shown that mental illness and those who suffer from mental illness face a great deal of stigma which is very much ingrained in the society due to the inaccurate and damaging portrayal of mental health patients in the media [11]. It is common to find mentally ill patients represented in negative ways especially in movies, newspapers, magazines, television shows, and advertisement. For example, previous studies have shown that over the past decades, mentally ill people have been portrayed in the media as individuals who are violent and criminal [12]. One such study has been conducted in New Zealand [13] where it analyzed a one-week sample of 128 children's television program. The findings concluded that almost half of the programs have portrayed mental illness in a negative way. This negative representation by the media will definitely influence their viewers' perception of mentally ill people.

It is also likely that public perception of mental illness in Malaysia is no different. Public perception may be influenced by the rising homicide cases and suicides among mentally ill patients. For example, the news report of a man who is said to be mentally unstable who was detained in the brutal murder of his elderly uncle and aunt [14]. Such news reports will influence the public's perception as they will tend to generalize that all individuals with mental illness as someone who is violent, restless and unpredictable. In addition, those with severe mental illness are viewed quite negatively by others compared to people who suffer from physical illness. So much so that many mentally ill patients withdraw from society and conceal their illness for fear of the stigma and discrimination that they will face [11].

A research was also carried out to investigate perception and attitude of an urban community towards mental illness in South Delhi [15]. The results revealed that there is a lack of awareness especially regarding bio-medical concept of mental illness. The respondents' knowledge on mental illness is also bounded with superstition based on the health seeking behaviour of the community. The findings showed that they preferred the tantric and ojha (also known as faith healers) as the health seeking places for mental illness to get rid of evil spirits. The lack of awareness among the people of this society about mentally ill people is most probably due to historical roots of their beliefs and cultures. This shows a need for health education in order to raise awareness on mental illness as well as help in reducing burden of morbidity in the community.

Apart from the media, people's ignorance of mental illness is another reason behind the stigma and discrimination. However, research into people's awareness and attitude towards mental health illness in Malaysia is still scarce. One such study was conducted on Malaysians' attitude towards mental illness [10]. The findings of the study indicated that there is a great deal of public ignorance. Most of the respondents ( 70 percent to over 90 percent) were unaware or were unable to provide the correct answers to questions asked to them about mental health and mental illness. Moreover, the findings also showed that the ignorance was higher among those in rural areas compared to urban people. Individuals' ignorance towards mental illness is severer as it could result in negative attitude towards people with mental illness. In fact, the findings of the study did indicate that negative attitude towards people with mental health was found to be prevalent among Malaysians. Although this study was able to provide empirical evidence of the lack of knowledge Malaysian had about mental illness, very little is known about why this is so.

Information is the key to educating the public. However, there appears to be a lack of health promotion on mental illness in Malaysia. There have been a few efforts done by the government to promote mental health, namely a national mental health promotion campaign was initiated under the annual thematic national Healthy Lifestyle campaign in 2000 and stress management was included into the Lifelong Health campaign in 2005. However, the progress and impact from these programmes are unknown due to lack of human resource to observe and push for outcome [9].

Taking into consideration the growing number of mental health problems among adolescents and teenagers, only a few research have investigated the perception and awareness of teenagers towards mental illness. There is indeed a need for such a study as this will provide not only an understanding of the level of awareness among this age group but would also provide some indication as to the need for a more systematic public health campaign targeted at young people. On the contrary, there have been a number of guidelines and training modules on mental health being developed for instance mental health care for different groups of the population. According to [16], research has shown that mental health promotion is most effective when it takes place in a person's early life, therefore school may be a favourable location for such programmes to take place. Thus, many health programmes have also been initiated like mental health service in the health clinics as well on mental health and stress management among school children based on a paper by [9]. These are a few of the efforts to destigmatise and to educate the Malaysian public 
especially school children on mental illness.

There are currently only a few published research reports and articles about health and wellness among teenagers especially secondary school students in Malaysia. In addition, the promotion of health and wellness is still lacking in relation to mental illness although people diagnosed with it has increased. Hence, this paper will report on a study conducted to examine secondary school students': i) awareness of mental illness and mental illness patients, ii) awareness of mental illness treatment and support as well as iii) attitudes and perceptions of mental illness.

\section{Methodology}

\subsection{Participants}

In line with the aim of the study which is to investigate the perception and awareness of Malaysian teenagers of mental health illness, secondary school students in Skudai, a district in Johor, a state in the South of Peninsula Malaysia were selected as participants of this study. The students are 118 form four students from a randomly selected government secondary school. The students were chosen because they represented teenagers who made up the 20 percent of Malaysians showing signs of psychiatric morbidity in 2011 as reported in [8]. Moreover, a growing number of secondary school students are not in their healthy state of mind and suffer from various kinds of mental health such as severe depression, anxiety and others as reported in a study [9].

Hence, there is a need to conduct a study to identify the awareness level of secondary school students of mental illness. The findings would be useful for public health campaigners and the ministry of health in their efforts to increase public health awareness on this important health issue. It is important to disseminate information and educate secondary school students on mental illness issues so that they will be better able to understand and manage this illness which is increasingly becoming a problem among this age group [9].

\subsection{Instruments}

The instrument used to collect the data was questionnaire. A set of questionnaire was developed based on a questionnaire used in previous study [17]. Some of the questions were adapted to meet the objectives of the study. The researchers have conducted a pilot study beforehand to measure the questionnaire's reliability and validity. A total of 30 secondary school students were involved in the pilot study.

The data collected were entered into SPSS Cronbach's Alpha internal consistency test. The result obtained from the pilot study was 0.88 which indicates a strong level of internal consistency. Cronbach's alpha of 0.6 is deemed sufficient to be an acceptable value for research purpose [18]. This is further supported that items with the reliability index value more than 0.7 can be used as a measuring tool to carry out a survey [19].

The questionnaire consisted of 63 questions and was divided into five main sections as shown in Table 1. Part A gathered basic personal details such as age, gender as well as history about mental illness among the respondents' friends, family members and others. Next is part B where the respondents have to choose at least one or more responses based on their understanding on mental illness. Generally, it enquired into their knowledge on different descriptions of mental illness patients, forms and symptoms of mental illness as well as possible treatment plans for mentally ill people.

Table 1. Description of the Items in the Questionnaire.

\begin{tabular}{llll}
\hline Section & Title & Question Type & No. of Item \\
\hline A & $\begin{array}{l}\text { Personal Details } \\
\text { Definition of Mental }\end{array}$ & Categorical & i-iii \\
B & $\begin{array}{l}\text { Multiple choice } \\
\text { Ilness }\end{array}$ & $1-5$ \\
C & $\begin{array}{l}\text { Awareness Level on } \\
\text { Mental Health Promotion }\end{array}$ & Likert scales & $7-19$ \\
D & $\begin{array}{l}\text { Attitude on Mental Illness } \\
\text { Awareness Level on }\end{array}$ & $\begin{array}{l}\text { Likert scales } \\
\text { Likert scales and } \\
\text { open-ended }\end{array}$ & $20-41$ \\
E & Mental Illness & $42-63$ \\
\hline
\end{tabular}

The questions in the latter sections were presented in the forms of Five-Point Likert Scale. Part $\mathrm{C}$ assessed the awareness of the respondents on mental health promotion in school and local mass media. Part D measured the respondents' perception of mental illness including the patients and its treatment. The last section in the questionnaire is Part $\mathrm{E}$ that determined the respondents' awareness level on mental illness facts, namely statistics, prevalence rates, treatment plans and available support group for mentally ill people in Malaysia. These types of questions are essential as they indicate the respondents' present knowledge.

\subsection{Data Analysis}

The responses received from the respondents were analyzed using the Statistical Package for Social Science software (SPSS) version 16. The results were presented through frequency counts, percentages and mean scores in the form of bar graph and table. In analysing the data, the Five-Point Likert Scale of ordinal measures of agreement ranging from strongly disagree (1) to strongly agree (5) was used in the questionnaire as shown in Figure 1.

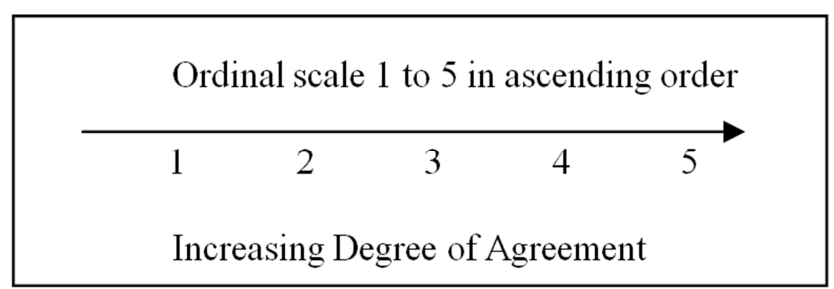

Figure 1. Five ordinal measures of agreement of Likert's scale.

This study is interested to investigate the students' awareness and perception of mental illness; hence there are two types of data analysis: i) The awareness or knowledge scale of the respondents were measured based on the frequency score and percentages. The respondents' responses as "agree", "strongly agree", "disagree", "strongly disagree" and "neutral" on given statements in the questionnaire will reflect their knowledge on mental illness. The statements 
given consist of correct and incorrect facts in relation to mental illness. Respondents who were able to identify the correct facts from the statements given were considered as having an awareness of mental illness; ii) The perceptions of the respondents were determined by the mean value where higher score represent a better perception of mental illness. A study has also utilized this range of mean value to determine the perception of the respondents [20]. The classification for the rating scale used is as follows [21]:

$$
\begin{gathered}
\text { 'Strongly Disagree' }=1.00<\text { mean score }<1.50 \\
\text { 'Disagree' }=1.50<\_ \text {mean score }<2.50 \\
\text { 'Moderately Agree' }=2.50<\text { mean score }<3.50 \\
\text { 'Agree' }=3.50<\text { mean score }<4.50 \\
\text { 'Strongly Agree' }=4.50<\text { mean score }<\text { _ } 5.00
\end{gathered}
$$

\section{Results, Discussion and Conclusions}

This section discusses the findings of the study based on the main questions asked in the questionnaire.

\subsection{Mental Illness}

As this research is interested in investigating students' awareness of mental illness, it was important to examine what are their definitions of mental illness. Hence, respondents were asked to choose from seven options which would best describe how they would describe a person who has mental illness. The analysis of the responses received is shown in Table 2.

Table 2. Respondents 'perception of mental illness patient.

\begin{tabular}{ll}
\hline Descriptions of mental illness patient & Percentages \\
\hline Someone who suffers from depression & $24.62 \%$ \\
Someone who is just ill/sick & $2.69 \%$ \\
Someone who is mentally disturbed & $33.08 \%$ \\
Someone who hears voices(schizophrenia) & $11.15 \%$ \\
Someone who is unable to care for themselves & $5.00 \%$ \\
Someone who suffers panic attacks & $8.46 \%$ \\
Someone who suffers anxiety & $15.00 \%$ \\
\hline
\end{tabular}

All seven definitions were chosen as a suitable description of a mentally ill person. The top three definitions chosen by the respondents were someone who is mentally disturbed, someone who suffers from depression and anxiety. Someone who is mentally disturbed was chosen by 33.08 percent of the respondents to describe patients with mental illness. 24.62 percent of students agreed that someone who suffers from depression and 15.00 percent of them chose someone who suffers anxiety. Then, 11.15percent of the students thought that mental illness patient was someone who hears voices (schizophrenia) and 8.46 percent believed that someone who suffers from panic attacks is mentally ill. A small percentage of the respondents, (5\%) also described mental illness patients as someone who is unable to care for themselves. Lastly, the remaining 2.69 percent of the respondents considered a person who is mentally ill as someone who is just ill/sick. Therefore, it can be concluded that the majority of the respondents viewed a person who has a mental illness as someone who is mentally disturbed.

Moreover, the respondents were inquired on various forms of mental illness in line with the aims of this study. The respondents were asked to choose from six conditions which would be the most common forms of mental illness based on their prior knowledge. The analysis of the responses is shown in Table 3.

Table 3. Respondents' perceptions on the different forms of mental illness.

\begin{tabular}{ll}
\hline Forms of mental illness & Percentages \\
\hline Delusion & $14.12 \%$ \\
Paranoia & $10.98 \%$ \\
Anxiety & $18.82 \%$ \\
Depression & $26.27 \%$ \\
Manic disorder & $15.29 \%$ \\
Schizophrenia & $14.51 \%$ \\
\hline
\end{tabular}

All six definitions were selected as the common forms of mental illness. The top three forms of mental illness chosen by the respondents were depression, anxiety and manic disorder. 26.27 percent of the respondents chose depression as a form of mental illness. Then, 18.82 percent of the respondents chose anxiety while 15.29 percent perceive manic depression as a symptom of mental illness. This is followed by schizophrenia and delusion where 14.51 percent and 14.12 percent of the respondents agreed that these are possible indicators of mental illness. Only a small percentage $(10.98 \%)$ of the respondents views paranoia as a symptom of mental illness. It can be concluded that majority of the respondents believed depression as a prevalent form of mental illness. Accordingly, all of the choices given are the correct forms of mental illness with depression and anxiety as the most common ones. Most of the respondents have moderate awareness level of mental illness as they have chosen one of the most common forms of mental illness that is depression.

The students' perceptions of the possible symptoms of mental illness were also important for this study. This is because it would provide an additional indication of the respondents' knowledge on mental illness. They were asked to select from six choices which would be the most likely symptoms of mental illness. The analysis of the responses received is shown in Table 4 .

Table 4. Respondents 'perceptions on the possible symptoms of mental illness.

\begin{tabular}{ll}
\hline Symptoms of mental illness & Percentages \\
\hline Possessed by evil spirits & $7.14 \%$ \\
Intense fear or phobia & $25.00 \%$ \\
Anxiety & $21.43 \%$ \\
Stress & $36.61 \%$ \\
Personal weakness & $7.14 \%$ \\
Poor upbringing & $2.68 \%$ \\
\hline
\end{tabular}

Table 4 shows the respondents' perceptions on the different symptoms of mental illness. All six symptoms listed were the 
possible symptoms of mental illness. The top three potential symptoms chosen by the respondents were stress, anxiety and intense fear or phobia. Based on the findings, 36.61 percent of the students chose being stress as the most possible symptoms of mental illness while 25 percent of them considered intense fear or phobia as a symptom of mental illness. 21.43 percent of the students selected anxiety as a potential symptom of mental illness. The top three choices chosen by the respondents were the correct possible symptoms of mental illness. This indicates that majority of the respondents have good awareness level of mental illness. However, a small number of respondents (7.14\%) chose personal weakness and being possessed by evil spirit as symptoms of mental illness. This appear to support the previous study which indicated that even people in urban community believed that mental illness is caused by supernatural beings and would seek treatment from faith healers rather than medical help [15]. Only 2.68 percent of them opted on poor upbringing as the likely symptoms for mental illness. Subsequently, it can be concluded that most of the respondents assumed stress as the most possible symptom for mental illness.

Table 5 shows the respondents' perception on potential treatment plans for people with mental illness. The students were asked to choose one out of six choices of suitable treatment plans for mentally ill people. It was significant as it will help to assess their understanding in relation to treatment for patients with mental illness.

Table 5. Respondents' perception on possible treatment plans for people with mental illness.

\begin{tabular}{ll}
\hline Symptoms of mental illness & Percentages \\
\hline Community services & $12.41 \%$ \\
Peer support group & $18.25 \%$ \\
Patients own will power & $10.95 \%$ \\
Traditional treatment & $4.74 \%$ \\
Psychosocial treatment & $33.94 \%$ \\
Medical treatment & $19.71 \%$ \\
\hline
\end{tabular}

There are six choices of potential treatment plans for mentally ill people. The best three healing plans preferred by the respondents were psychosocial treatment, medication and peer support group. 33.94 percent of the respondents believed that psychosocial treatment is the best possible treatment available for mental patients. Meanwhile, 19.71 percent of the students selected medication treatment and 18.25 percent preferred peer support group. 12.41percent of the respondents chose community services while 10.95 percent of them chose patients own will power as the promising treatment for mental illness patients. Only 4.74 percent opted for traditional treatment as an alternative for mental illness treatment. Therefore, it can be concluded that most of the respondents considered psychosocial treatment as the most promising treatment plan for people with mental illness.

There are four terms that are often used to refer to mental illness and the respondents were asked to select which would be the most common one. This particular question will give us an insight on the respondents' view towards mental illness.

Table 6. Respondents' perception on terms to refer to mental illness.

\begin{tabular}{ll}
\hline Symptoms of mental illness & Percentages \\
\hline Mental disorder & $44.09 \%$ \\
Mental addiction & $6.45 \%$ \\
Mental dysfunction & $21.51 \%$ \\
Mental disease & $27.96 \%$ \\
\hline
\end{tabular}

Figure 6 shows the respondents' perceptions on terms which often referred to mental illness. 44.09 percent of the respondents chose mental disorders while the other 27.96 percent of them selected mental disease as the suitable terms to refer to mental illness. Next, 21.51percent described mental dysfunction while the rest of the respondents, 6.45 percent chose mental addiction as the terms related to mental illness. It can be concluded that majority of the respondents regarded mental disorder as the term which is most suitable when referring to mental illness. The top two choices chosen by the respondents are the correct terms to refer to mental illness. Consequently, the result shows that the respondents have high awareness level of mental illness as majority of them have chosen the right terms when referring to mental illness.

\subsection{People Who Suffer from Mental Illness}

One of the objectives of this study is to measure the students' awareness level of mental illness, thus it is crucial to look into what are their perception of mental illness patients. The questions examine the respondents' knowledge with regard to mentally ill people, namely the prevalence rate of mental illness, present statistics of patients and others. Table 7 shows the awareness level of the respondents of mental illness.

Table 7. Respondents' awareness level of people who suffer from mental illness.

\begin{tabular}{|c|c|c|c|c|c|c|}
\hline \multirow{2}{*}{ No. } & \multirow{2}{*}{ Items } & \multicolumn{5}{|c|}{ Likert Scale } \\
\hline & & SD & D & $\mathbf{N}$ & $\mathbf{A}$ & $\mathbf{S A}$ \\
\hline 46. & $\begin{array}{l}\text { More teenagers are } \\
\text { suffering from } \\
\text { mental health } \\
\text { problems now than } \\
\text { before. }\end{array}$ & $\begin{array}{l}6 \\
5.1 \%\end{array}$ & $\begin{array}{l}13 \\
11.0 \%\end{array}$ & $\begin{array}{l}23 \\
19.5 \%\end{array}$ & $\begin{array}{l}50 \\
42.4 \%\end{array}$ & $\begin{array}{l}26 \\
22.0 \%\end{array}$ \\
\hline 49. & $\begin{array}{l}\text { Mental illness can } \\
\text { affect people of } \\
\text { any age, race, } \\
\text { religion or income. }\end{array}$ & $\begin{array}{l}4 \\
3.4 \%\end{array}$ & $\begin{array}{l}5 \\
4.2 \%\end{array}$ & $\begin{array}{l}32 \\
27.1 \%\end{array}$ & $\begin{array}{l}42 \\
35.6 \%\end{array}$ & $\begin{array}{l}35 \\
29.7 \%\end{array}$ \\
\hline 51. & $\begin{array}{l}\text { Mental illness } \\
\text { could occur to } \\
\text { people who have } \\
\text { had an accident or } \\
\text { a trauma during } \\
\text { childhood. } \\
\text { Total average }\end{array}$ & $\begin{array}{l}16 \\
13.7 \%\end{array}$ & $\begin{array}{l}41 \\
35.0 \%\end{array}$ & $\begin{array}{l}43 \\
36.8 \%\end{array}$ & $\begin{array}{l}14 \\
12.0 \%\end{array}$ & $\begin{array}{l}3 \\
2.6 \%\end{array}$ \\
\hline
\end{tabular}

Table 7 shows the awareness level of the respondents on mental illness. From the findings, it could be seen that the majority of the respondents, $(42.4 \%)$ agreed that more teenagers are suffering from mental health problems now 
than before. This reflects that the respondents are aware that there are rising trends of mental illness sufferers among teenagers. According to findings from a pilot study carried out on the mental health of secondary school children has shown that a number of the students had symptoms of mental illness such as anxiety disorders and depression [9]. The respondents also agreed to the statement "Mental illness can affect people of any age, race, religion or income" with the total percentage of 35.6 percent. Hence, the findings clearly show that the students are aware and believe that anyone is vulnerable to mental illness, including themselves. An understanding of the nature of this illness and how it can affect different people will have a positive impact on how mentally ill patients are perceived.

Moreover, the respondents appear to be unsure that mental illness could occur in people who have had an accident or a trauma during childhood with a reported percentage of the respondents (36.8\%) choosing the neutral option for this particular question. This indicates that the respondents are unaware that mental illness can occur to a person who experiences any overwhelming and uncontrollable experience in their childhood. In fact a study on mental illness reported that it can start as early as in adolescence based on national study of adults with mental health disorder $[2]$.

It is important to note that the overall percentages based on the figures in Table 2. Although, 29.4 percent and 11.5 percent from the total average percentage of respondents stated positive answers, while 5.75 percent and 12.5 percent of them gave negative answers, a much higher percentage $(40.9 \%)$ chose 'neutral' as their responses. The higher total percentages of respondents who chose 'neutral' answers are rather alarming as this may indeed be a sign of the students' lack of knowledge about mental illness.

\subsection{Mental Illness and Its Treatment}

This study is also concerned in exploring students' attitude on mental illness; hence it is significant to investigate what are their perceptions of mental illness patients in relation to the potential treatment and the after effect from the rehabilitation process. The analysis in Table 8 shows the respondents' perception of mental illness and its treatment.

Table 8. Respondents 'perception on mental illness and its treatment.

\begin{tabular}{|c|c|c|c|c|c|c|c|c|}
\hline \multirow{2}{*}{ No. } & \multirow{2}{*}{ Items } & \multicolumn{5}{|c|}{ Likert Scale } & \multirow[t]{2}{*}{ Mean } & \multirow[t]{2}{*}{ Response } \\
\hline & & SD & D & $\mathbf{N}$ & $\mathbf{A}$ & SA & & \\
\hline 28. & $\begin{array}{l}\text { The care and support of family and friends can help people } \\
\text { with mental illness to get rehabilitated. }\end{array}$ & $\begin{array}{l}4 \\
3.4 \%\end{array}$ & $\begin{array}{l}3 \\
2.5 \%\end{array}$ & $\begin{array}{l}9 \\
7.6 \%\end{array}$ & $\begin{array}{l}45 \\
38.1 \%\end{array}$ & $\begin{array}{l}57 \\
48.3 \%\end{array}$ & 4.25 & Agree \\
\hline 32. & Mental illness is treatable. & $\begin{array}{l}3 \\
2.5 \%\end{array}$ & $\begin{array}{l}0 \\
0 \%\end{array}$ & $\begin{array}{l}20 \\
16.9 \%\end{array}$ & $\begin{array}{l}64 \\
54.2 \%\end{array}$ & $\begin{array}{l}31 \\
26.3 \%\end{array}$ & 4.02 & Agree \\
\hline 33. & $\begin{array}{l}\text { After people with mental illness are treated and } \\
\text { rehabilitated, we still should not make friends with them. }\end{array}$ & $\begin{array}{l}50 \\
42.4 \%\end{array}$ & $\begin{array}{l}41 \\
34.7 \%\end{array}$ & $\begin{array}{l}17 \\
14.4 \%\end{array}$ & $\begin{array}{l}9 \\
7.6 \%\end{array}$ & 1 & 1.09 & Disagree \\
\hline
\end{tabular}

Table 8 shows the attitude of the respondents on mental illness and its treatment. From the findings, it could be seen that the highest mean was 4.25 where the respondents agreed to the statement that care and support of family and friends can help people with mental illness get rehabilitated. This shows that the respondents believe mental illness patients should obtain love, attention and aid from their loved ones in order for them to recover from this disease. This is because a person's immediate family plays an important role in helping them to obtain proper diagnosis by an expert and the right treatment [22].

Accordingly, this was also confirmed by majority of the respondents who agreed that mental illness is treatable with a reported mean value of 4.02. This reflects that the respondents have positive perception of mental illness as they believed that people who have a mental illness could be treated and there are chances for recovery. Thus, early identification and intervention of mental illness is exceptionally crucial as assessing effective treatment earlier will bring better outcome. Schools should take necessary actions to identify and provide proper treatment to students with symptoms of mental illness as the illness is proven prevalent among children based on previous studies [7, 9].
This is because it enables adolescents to succeed in school, to develop socially and to fully experience the developmental opportunities of childhood.

The respondents also disagreed that even after people with mental illness are treated they are still considered more dangerous than normal people and that after treatment and rehabilitation, people should not make friends with people with mental illness. For the above two statements, a reported mean value of 2.09 and 1.90 were obtained respectively. This shows that the respondents have a positive attitude towards mental illness patients as they give support and even believe that mental illness sufferers should be accepted in the society once they have recovered. The students' positive attitude on mental illness and its treatment are significant as it indicates that they will not have stigma towards mental illness sufferers. Stigma that surrounds mental illness is very severe as it could lead to discrimination and prejudice. This was supported by the study where stigma is defined as a stereotype that portrays a certain group negatively and it is considered "social" since it is collectively agreed upon demographic membership [23]. Stigma and discrimination could be generally considered as a major barrier that discourages mental illness patients and their families from 
getting the help and necessary treatment.

As a whole, majority of the students reflect positive attitude on mental illness and its treatment. This may results from health programmes that have been initiated among school children like mental health service in the health clinics as well as on mental health and stress management [9]. Positive attitude is essential as it will help more people with mental illness to come forward and obtain necessary help which are important for their recovery and wellness.

It is clear from Table 8 that, 26.3 percent and 13.0 percent from the total average percentage of respondents stated positive answers. Meanwhile, 15.2 percent and 20.9 percent of them gave negative answers. The remaining 24.5 percent chose neutral responses. Accordingly, the respondents have moderate perception with the total average mean of 2.91 . This indicates that the respondents have a rather positive attitude on mental illness and its treatment. This overall positive attitude that the respondents show may be an encouraging indication that mental health patients who have undergone treatment may be better accepted by the community and may experience less stigma and discrimination.

\subsection{Mental Health Support}

Mental health support refers to the support given by the government and non-government association. Mental health support covers a wide range of efforts, namely raising mental health awareness, combating stigma and increasing understanding as well as providing emotional support, practical help and information. All of these are vital to aid mental illness patients' treatment and recovery process Table 9 shows the respondents' awareness level of mental health support in Malaysia.

25 percent of the respondents acknowledged a few mental health facilities available in Malaysia that are Hospital Tanjung Rambutan, Hospital Tampoi, Hospital Bahagia, Hospital Kempas, Malaysian Psychiatric Association and clinic. This indicates that a number of respondents are aware of the facilities but only the prominent ones in Malaysia.

However, the majority of the respondents (81\%) are still oblivious on mental health associations in Malaysia. This also indicates that the respondents are not aware of any associations available in Malaysia that provide rehabilitation services, offer support for positive attitudes towards mental health, plan and execute mental health programmes to mental illness patients. There are also some of them stated a few mental health associations such as Malaysia Mental Health Association and Malaysian Psychiatric association which most likely had been cited in the questionnaire itself.

In addition, the majority of the respondents stated that they can obtain information about mental health from various sources. They indicated that the major resources which provide information on mental health are mass media, internet, magazines, hospital, school, and parents. This shows that information about mental illness, like other health information, is not something scarce and needed information can be easily obtained nowadays. Yet, some of respondents pointed out that they have gained some information about mental illness while answering the questionnaire. This finding clearly suggests that although information about mental illness is available, there is also a great deal of misinformation especially on the internet. Young adults such as the respondents in this study need to be guided on ways to search for the correct information from reliable sources. Relevant agencies such as the Ministry of Health should use online medium as an important tool to reach and educate young people about mental health as this is the medium which appeals more to the younger generation.

Table 9. Respondents' awareness level on mental health support.

\begin{tabular}{|c|c|}
\hline Open-ended questions & Responses \\
\hline $\begin{array}{l}\text { Do you know of any } \\
\text { mental health facilities in } \\
\text { Malaysia? If yes, please } \\
\text { name the facilities. }\end{array}$ & $\begin{array}{l}\text { No }(75 \%) \\
\text { Yes }(25 \%) \\
\text {-Hospital Tanjung Rambutan, Hospital } \\
\text { Tampoi. Hospital Bahagia, Hospital Kempas, } \\
\text { Malaysian Psychiatric Association and Clinic }\end{array}$ \\
\hline $\begin{array}{l}\text { Do you know of any } \\
\text { mental health associations } \\
\text { in Malaysia? If yes, please } \\
\text { name the associations. }\end{array}$ & $\begin{array}{l}\text { No }(81 \%) \\
\text { Yes }(19 \%) \\
\text { Malaysia Mental Health Association and } \\
\text { Malaysia Psychiatric Association }\end{array}$ \\
\hline $\begin{array}{l}\text { Where do you get } \\
\text { information about mental } \\
\text { health? }\end{array}$ & $\begin{array}{l}\text { Magazines, Friends, Mass Media, Internet, } \\
\text { Hospital, School and Parents }(70 \%) \\
\text { This questionnaire itself }(10 \%) \\
\text { Do not know }(20 \%)\end{array}$ \\
\hline $\begin{array}{l}\text { Do you know anyone who } \\
\text { suffers from mental } \\
\text { illness? If yes, please } \\
\text { specify (e.g. friends, } \\
\text { mother, father, etc.) }\end{array}$ & $\begin{array}{l}\text { No }(65 \%) \\
\text { Yes }(35 \%) \\
\text { - family members, friends and people in my } \\
\text { neighbourhood }\end{array}$ \\
\hline $\begin{array}{l}\text { Have you ever } \\
\text { encountered any mental } \\
\text { health issues or mental } \\
\text { illness in your lives? If } \\
\text { yes, please specify. }\end{array}$ & $\begin{array}{l}\text { No }(65 \%) \\
\text { Not sure }(10 \%) \\
\text { Yes }(25 \%) \\
\text {-stress while studying and doing homework, } \\
\text { depression, lack of self-confidence } \\
\text { Public talk and forums from mental health }\end{array}$ \\
\hline $\begin{array}{l}\text { Which of these are } \\
\text { possible forms of support } \\
\text { and help for people with } \\
\text { mental illness and their } \\
\text { family? (Please tick }(\sqrt{ }) \\
\text { where applicable) }\end{array}$ & $\begin{array}{l}\text { association (10\%) } \\
\text { Family to family education groups (10\%) } \\
\text { Online peer support for adults with mental } \\
\text { illness (15\%) } \\
\text { Mental illness management and recovery (e.g. } \\
\text { daily exercising, gardening, etc.) (30\%) } \\
\text { Psychiatric services (35\%) }\end{array}$ \\
\hline
\end{tabular}

Most of the respondents also mentioned that they did not know anyone who suffers from mental illness and never encountered any mental health issues or mental illness in their lives. This may indicate that the respondents only have knowledge about mental health through their reading and never deal with real mental health problems. Nevertheless, there are a few of the respondents which have seen and dealt with mental health sufferers as they are someone among their own family, friends and even in neighborhood.

Interestingly, although a large majority of the respondents (65\%) admitted having never encountered any mental health issues or problems, 25 percent of the respondent acknowledged that they have experienced some form of mental illness in their lives which result from stress, depression and even feeling inferior of themselves. In addition, the majority of the respondents also believed that the best forms of 
support and help for people with mental illness and their family are psychiatric services as well as mental illness management and recovery (e.g. daily exercising, gardening, etc.). This is a positive indication that the respondents agree that people with mental problems should acquire professional help from qualified psychiatry, it is unfortunate that they are not aware of the available psychiatrics support and services. They also appear to understand the importance of family support and leisure activities in helping alleviate problems and stress in people's life.

Unfortunately, 88 percent of the respondents are unaware of any organizations that offer any of the above support for mental illness patients and their family. As previously mentioned, there were 25 percent of the respondents admitted experiencing some form of mental illness. This appears to be higher than what was previously reported which was 20 percent [8]. Of course this figure is inconclusive and reflects the student's perception rather than actual reported case, however, it is still worrying to know that 25 percent of the respondents have experienced some form of mental illness but unfortunately almost 90 percent of them have shown that they are not aware of the support. This clearly indicates the need for a more systematic and targeted campaign to ensure that the public is aware of the institutional support systems that are available for those who are suffering from mental illness. It is clear from this finding that a great deal of promotion and education is needed to increase public's awareness and understanding of mental illness [24].

Lastly, 73 percent of the respondents also believed that mental health-related stigma and discrimination has not changed in the past year. This may probably occur because of the mass media influence as they still portray mental health problems negatively. The mental illness patients are also usually being portrayed as violent and impulsive which largely contribute towards negative attitude of the audiences. The negative portrayal of mental illness in the media can have a damaging effect on the public's perception of people with mental illness A study has shown that stigma towards mental illness can cause patients to hide from the community because of fear of discrimination [11]. This is further supported by the small minority of the respondents who have pointed out that the stigma has decreased slightly as there have been improvement in medical treatment and that people are more educated and open minded towards mental health issues these days.

In short, the following conclusion could be drawn from the study. Firstly, this study has shown that in general the awareness level of the respondents with regard to mental illness is fairly moderate with regard to mental illness in Malaysia. As for mental illness treatment, although patients have a positive perception of mental health treatment, they show a serious lack of awareness when it comes to the service and support system that are available around them. They were only able to mention a few prominent mental health facilities in Malaysia based on their prior knowledge. The findings also revealed that most of the respondents in this study have moderately positive attitudes towards mental illness patients.
Nonetheless, they also agree that people with mental illness have unpredictable behavior and difficult to make good friends This may occur as a result of the influence of mental health-related stigma and discrimination which the respondents admitted have not shown any significant changes in this past year.

\section{Implications and Recommendations of the Study}

One of the implications that can be drawn from this study is both government and non-government organizations should play a bigger role in taking the lead to tackle issues related to mental health. In addition, the mass media must also work hand in hand in supporting such efforts for instance they could broadcast systematic public health campaign to increase mental health awareness among Malaysians. This is essential as mass media; especially online media such as websites and social networking sites is a powerful tool for spreading information to society which $\mathrm{t}$ will help to ensure successful dissemination of vital information to all sections of the society. In addition, engagement with mass media will help to provide deeper understanding about mental illness as it could correct the misconception and social stigma that surround mental illness [22].

Mental illness could be experienced by anyone regardless of age, gender, race and beliefs. Awareness and positive attitude towards people suffering from mental illness can give a great deal of help to save them from mental health related problems. It is recommended that government through Ministry of Health and Ministry of Education should work together to promote better mental health programs in school to get rid of the stigma and discrimination associated with mental illness. The Ministry of Health should review health service to re-orientate its focus on mental health. This will help to ensure that mental health gain as much attention as other physical health issues. Mental health education is beneficial as it provides not only knowledge to the students but also helps contribute towards healthier family and community. This is supported that the negative attitude of people towards mental illness could be change through three approaches, specifically education, contact and protest [24].

Stress and unhealthy lifestyles could contribute towards serious health problems including mental illness [10]. Thus, the students should also be encouraged to join healthy activities with their peers to reduce their level of stress and anxiety. This is because these are the two symptoms which are most often associated with mental illness. The schools could organize more health activities such as outdoor sports and healthy lifestyles campaign to promote not only good mental health but also physical health.

Last but not least, more research into mental health issues at the local level is very much needed to offer evidence on mental health issues and ways in which these issues can be better managed and prevented. Future studies should also look into this matter more seriously and for wider scope as there is still a 
wide gap in knowledge with reference to mental health issues in Malaysia.

\section{Acknowledgements}

We would like to convey our gratitude to Universiti Teknologi Malaysia as the sponsor for this project under the Research University Grant (RUG) Vote No. 04J51 headed by Assoc Prof Dr Hadina Habil.

\section{References}

[1] Swami, V., T. Chamorro-Premuzic, D. Sinniah, T., Maniam, K., Kannan, D. S., \& Furnham, A. (2007). General health mediates the relationship between loneliness, life satisfaction and depression. Social Psychiatry and Psychiatric Epidemiology, 42, 161-166.

[2] Kesseler, R. C., Berglund, P., Demler, O., Jin, R., Kathleen, R. M., \& Walters, E. E. (2005). Lifetime Prevalence and Age-of-onset distributions of DSM-IV disorders in the national comorbidity survey replication. Arch Gen Psychiatry; 62:593-601.

[3] Meldrum, L., Venn, D., \& Kutcher, S. (2009). Mental health in schools: How teachers have the power to make a difference. Health \& Learning Magazine.

[4] Zivin, K., Eisenberg, D., Gollust, S., \& Golberstein, E. (2009). Persistence of Mental Health Problems and Needs in a College Student Population. Journal of Affective Disorders 117(3): 180-185.

[5] World Health Organization. (2003). The Mental Health Context: Mental Health Policy and Service Guidance Package. Geneva: WHO.

[6] Ministry of Health Malaysia. (2008). Psychiatric Morbidity. 3rd National Health and Morbidity Survey, 2006. Institute for Public Health, Ministry of Health Malaysia.

[7] Teoh, H. J. (2010). A Survey of Urban Child and Adolescent Mental Problems in an Urban Malaysian Population. MJP Online Early.

[8] Mental health problems afflicting teens increasing. (2012, October 8). The Star Online. Retrieved from http://www.thestar.com.my/News/Nation/2012/10/08/Mentalhealth-problems-afflicting-teens-increasing-says-Liow.aspx.

[9] Ang, K. T. (2011). Current Perspective in Mental Health. 3rd Asia Pacific Conference on Public Health.

[10] Yeap, R., \& Low, W. Y. (2009). Mental health knowledge, attitude and help-seeking tendency: a Malaysian context. International Medical University. Kuala Lumpur. Malaysia.
[11] Corrigan, P. W. (1998). The impact of stigma on severe mental illness. Cognitive and Behavioral Practice, 5, pp 201-222.

[12] Cutcliffe, J. R., \& Hannigan, B. (2001). Mass media, "monsters" and mental health clients: The need for increased lobbying. Journal of Psychiatric and Mental Health Nursing, 8(4), 315321.

[13] Wilson, C., Nairn, R., Coverdale, J., \& Panapa, A. (1999). Mental illness depictions in prime-time drama: Identifying the discursive resources. Australian and New Zealand Journal of Psychiatry, 33(2), 232-239.

[14] Mentally ill man remanded over double murder. (2012, June 22). The Star Online. Retrieved on fromhttp://webcache.googleusercontent.com/search? $\mathrm{q}=$ cache: 1157Dmmk6isJ:www.thestar.com.my/news/story.asp\%3Ffile\% 3D/2012/6/22/courts/11529047+\&cd=1\&hl=en\&ct=cl.

[15] Salve, H., Goswami, K., Sagar, R., Nongkynrih, B., \& Sreenivas, V. (2013). Perception and attitude towards mental illness in an urban community in South Delhi - A community based study. Indian Journal of Psychological Medicine. Vol 35; Issue 2. New Delhi, India.

[16] Clarke, A. M., \& Barry, M. (2010). An evaluation of the Zippy's Friends emotional wellbeing programme for primary schools in Ireland.

[17] Ng, P., \& Chan, K. F. (2000). Sex differences in opinion towards mental illness of secondary school students in Hong Kong. International Journal of Social Psychiatry 46. pp.79-88.

[18] Nunnally, J. C. (1976). Psychometric theory. New York: McGraw-Hill.

[19] Mohd Najib Abd Ghafar. (1999). Penyelidikan Pendidikan. Skudai, Johor. Penerbit Universiti Teknologi Malaysia.

[20] Mohamed Amin, Embi., \& Azmi, Abdul Latiff. (2002). Teachers Perception towards an Interactive Web-Based Model for Learning to Learn English. Proceeding of Konvensyen Teknologi Pendidikan Kebangsaan Ke-15, 201- 206.

[21] Abd. Majid, M. Z., \& McCaffer, R. (1997). Assessment of Work Performance of Maintenance Contractors in Saudi Arabia, Journal of Management in Engineering. pg 91.

[22] Che Rozniza, Azizan., Asbah, Razali., \& Rajalingam, Pillai. (2013). Promoting Positive Mental Health among Students in Malaysia. Psychology and Behavioral Sciences; 2(2): 73-82.

[23] Devine, P. G. (1989). Stereotypes and prejudice: Their automatic and controlled components. Journal of Personality and Social Psychology, 56(1), 5-18.

[24] Corrigan, P., Edwards, A., Green, A., Diwan, S., \& Penn, D. (2001). Prejudice, social distance, and familiarity with mental illness. Schizophrenia Bulletin, 27(2), pp 219-225. 